\title{
Wolves on the Hunt: The Behavior of Wolves Hunting Wild Prey
}

By L. David Mech, Douglas W. Smith, and Daniel R. MacNulty. 2015. University of Chicago Press, 1427 East 60 th Street, Chicago, IL, USA, 60637. 208 pages, 50.00 USD, Cloth.

To be honest, I was a bit giddy having the opportunity to review Wolves on the Hunt given the subject matter and the well known wolf biologists who wrote it. The book is a fascinating account of the hunting behaviour of wolves. Nowhere could the title of a text so simply, yet accurately, reflect its contents. Each chapter is extremely detailed and exhaustive, covering all known wolf prey and how they hunt them. This truly is the capstone to first author Dave Mech's outstanding $>55$ year career studying wolves, and the painstaking time involved in writing this all-encompassing book on wolf predation with first-hand account descriptions of wolves hunting various prey is a tribute to all three authors. It takes endless hours of dedication and perseverance to make these observations and, led by Mech, the authors' own observations dominate the contents of most chapters.

The book description does a great job of summarizing the document's contents as well as the importance of this tome, in stating, "The interactions between apex predators and their prey are some of the most awesome and meaningful in nature - displays of strength, endurance, and a deep coevolutionary history. And there is perhaps no apex predator more impressive and important in its hunting - or more infamous, more misjudged - than the wolf. Because of wolves' habitat, speed, and general success at evading humans, researchers have faced great obstacles in studying their natural hunting behaviours. The first book to focus explicitly on wolf hunting of wild prey, Wolves on the Hunt seeks to fill these gaps in our knowledge and understanding. Combining behavioural data, thousands of hours of original field observations, research in the literature, a wealth of illustrations, and-in the e-book edition and online-video segments from cinematographer Robert K. Landis, the authors create a compelling and complex picture of these hunters. The wolf is indeed an adept killer, able to take down prey much larger than itself. While adapted to hunt primarily hoofed animals, a wolf - or especially a pack of wolves - can kill individuals of just about any species. But even as wolves help drive the underlying rhythms of the ecosystems they inhabit, their evolutionary prowess comes at a cost: wolves spend one-third of their time hunting - the most time consuming of all wolf activities - and success at the hunt only comes through travelling long distances, persisting in the face of regular failure, detecting and taking advantage of deficiencies in the physical condition of individual prey, and through ceaseless trial and error, all while risking injury or death. By describing and analysing the behaviours wolves use to hunt and kill various wild prey - including deer, Moose, Caribou, Elk, Dall Sheep, Mountain Goat, bison, Musk Oxen, Arctic Hare, beavers, and oth-
ers-Wolves on the Hunt provides a revelatory portrait of one of nature's greatest hunters."

Wolves on the Hunt is organized into 10 chapters, including the Introduction, which is not an official chapter but is nonetheless very critical in setting the stage for the rest of the book in countering the perception of the wolf as a 'killing machine'. At first glance, the reader might think that wolves can kill any prey item with ease but we learn that this is the furthest from the case as wolves have been killed by many of their prey, including White-tailed Deer, one of the wolf's smaller, regularly preyed upon food items. Thus, the central problem for wolves on the hunt is to kill without being killed (p. 1). We learn that prey have many anti-predator adaptations including herding, bunching up to protect young, yarding, birth-pulsing (or swamping), spreading out, nomadism, migration, sheer size and strength, long, shaggy hair, thick hides, standing their ground, outright endurance, speed, antler defence, attacking/chasing wolves, reaching steep rugged terrain like cliffs/ ledges, and escaping to water (Ch. 1-8). Thus, wolves are adapted to travelling many miles to find vulnerable members of each prey species. Wolf pack hunting size is more a function of the survival of pups and adults than for hunting purposes since the larger the pack, generally the less food obtained per wolf and a lower participation rate by pack members (p. 4). For example, with wolves hunting Elk, success peaks at just four wolves although living in larger packs allows older wolves to participate selectively in hunts (p. 4, 88). In fact, only with the wolves' largest prey, bison, does hunting success increase across larger pack sizes (up to 9-13 members; p. 5, 111, 126). The Introduction concludes with a description of the stages of a wolf hunt (p. 8-9) including search, approach, watch, attackgroup, attack-individual, and capture. The attack-individual phase of the hunt is the make-or-break stage as this phase of the hunt either ends in failure or the capture phase.

As we move into the chapters with wolves interacting with individual prey species (Ch. 1-8), the reader will find consistency in presentation where each section begins with an introduction that describes each prey's evolutionary adaptations to avoid predation by wolves, as well as specific wolf adjustments to survive on their mostly ungulate (hoofed animal, Ch. 1-7) diet. These adaptations vary given the species of prey and general habitat conditions but the reader gets the picture of the wolf as a very adaptable, relentless species that is highly intelligent and uses the terrain to its advantage from mountain to desert to tundra habitat. The heart of these chapters are the hunting accounts, with most chapters having ca. 50 reports per species, including for the wolf's smallest regularly documented food 
source, Arctic Hare (p. 147-155). These detailed observations are intended to "immerse the reader in the wolf's life as this intrepid creature strives to find, catch, and kill its wide variety of prey" (p. xii). And the authors do just that, providing many anecdotal reports of wolves hunting prey that, when taken together, provide an exemplary portrait, and rich data source, of wolves on the hunt. These chapters each finish with a conclusion that nicely summarizes the main findings from wolves interacting with their various prey items. In my opinion, this is the most important and succinct section of each chapter as they provide good reference material for the intrepid student looking for literature citations and quotes from this book, which can be found in abundance. The low success rate per hunt and the persistence of wolves in finding vulnerable individuals, which are usually young, old, and infirm members of each species, to prey upon are probably the most important themes that we take away from the book. And we learn that Elk might be the most perfect wolf prey, being a compromise of speed and strength that wolves seem to take preferentially, where available (p. 63). This section resonated with me as I have often watched wolves interact with and feed on Elk during my many trips to Yellowstone National Park (for more, see My Yellowstone Experience). Finally, we learn that deep snow is the ultimate equalizer for wolves and snow conditions are critical in all of the accounts, especially that described for White-tailed Deer, Elk, and bison (Ch. 1, 4, and 6).

The conclusion of the book is relatively short, at just five pages (pg. 159-163), but it provides an excellent summary and context for what the reader has digested in the previous sections. The authors note (p. 159) that the general perception might be that wolves can kill just about anything but modern scientists greatly differ from old-time naturalists and current laypeople in their approaches to gathering information and making conclusions about wolves and their behavior. It has been discovered that once prey survives for 1-2 years, many commonly reach old age at 10-20 years of age, and some prey species are so fit they do not even try to avoid wolves, contrary to the 'ecology of fear' idea ( $p$. 159). This is because wolves have to respond to the risk of injury from dangerous prey (including even deer), so they make trade-offs between acquiring food and safety (p. 160). Therefore, wolves generally are only able to kill calves, fawns, and older members of prey populations along with individuals that are diseased, disabled, or in poor condition (p. 161). Occasionally circumstances change whereby a higher proportion of vulnerable individuals are suddenly available, such as during deep snows, prolonged drought, or a sudden birth pulse of young (p. 162). The net result of wolves selecting prey over eons is that prey gradually gets faster, smarter, and more alert in this age-old evolutionary arms race. These processes have helped shape the fleetness of the deer, the alertness of the Elk, and the aggressiveness of the Moose (p. 163).
One subtle thing that I noticed, which might not be gleaned by even trained ecologists upon reading the book, is the fact that national parks played such a critical, underlying role throughout the book. In fact, Superior National Forest (NF) in Minnesota and some remote areas of Canada and Alaska are about the only major exceptions. Much of the wolf-deer interactions were documented in Superior NF as wolves had been fully protected there (similar to a national park) until very recently, and the area is remote making it difficult for human access. However, without Isle Royale, Yellowstone, and Denali National Parks in the United States, and Wood Buffalo National Park in Canada, much of Wolves on the Hunt would be incomplete. There are a few reasons for this: (1) scientists can generally study wildlife with less political interference in national parks than in most areas; (2) wildlife lives mostly undisturbed in these areas making them ideal study sites for researchers; (3) there is more infrastructure conducive to studying predator-prey interactions including departments set up for studying these systems, and money for equipment and researchers' salaries; and (4) the intense public interest in national parks makes them an ideal place where results will be picked up by not only scientific outlets (e.g., journals), but also by newspaper reporters, magazines, books, TV newscasts, and nature documentaries. This often feeds into increased funding, which is typified in Yellowstone where a large percentage of the wolf project is funded by private donors. Being from the Northeast U.S., I am envious of the relative lack of such national parks in this area, as well as the comparable lack of infrastructure, at least as of now, to support such studies (say of Eastern Coyotes/coywolves and White-tailed Deer).

The book is well illustrated with tables and figures summarizing data necessary for each chapter. The pictures (in black and white) were a very nice addition to each chapter, 'bringing the words alive' in seeing hunting wolves and their prey. In addition there was a glossy section of 33 colour pictures. These were exceptional, although oddly they were all repeats from some of the black and white pictures found within each chapter. However, the colour images were shown at such a better resolution that this was not necessarily a bad thing. In addition, I watched the accompanying video-clips after I had read the hardcover. This was a very satisfying way to enjoy the 18 video sequences and relate them to the book that I had just finished. There was 64 $\min 35 \sec (64: 35)$ of predator-prey interactions with the shortest segment being 1:12, the longest 9:19, and the average time 3:35, with all scenes filmed within Yellowstone National Park. The clips, including 14 focused on wolves hunting Elk and four on bison, were unedited so some were very raw showing complete kill sequences (including on bull, calf, and cow Elk) that might make some folks squeamish - yet it totally fits this book. The detail of these videos is unparalleled for wolf predation events, a tribute to film-maker Bob Lan- 
dis' dedication to his craft. And they provide an excellent context to the hunting accounts found in the text, and even though the videos focus on just two of the wolf's prey (i.e., Elk and bison), the reader gets a definite feel for what it is like for wolves to be on the hunt.

I have a few minor criticisms, which certainly does not distract from all but the closest read. One, I noted quite a few minor typos. Most of these were in the first-hand account observations of wolves hunting various prey items. Being a field researcher myself, I can easily see the challenge of converting field notes to book text. Fortunately, these errors do not affect the overall read. Two, the book is so detailed that it can be very tedious to read from cover-to-cover like I did. The great thing, however, is that the book is simple to understand and is organized and presented in a very straightforward manner where not every single account has to be read in-depth to get the gist of the text. If one chooses to comprehend every account, it will take a long time to read, which again is a tribute to the years of effort put into this book. Three, the Introduction chapter could have a couple of improvements. First, it should simply be labelled as Chapter 1 as I felt that this was a vital chapter setting up the remainder of the book, especial- ly following the authors' concisely written Preface (p. xi-xii). As it stands now, it is not labelled as a chapter, yet Chapter 9 is the Conclusion, which is a perfect complement to what we read about in the Introduction. Secondly, because the Introduction has lots of really good information on wolves and their prey, I thought that it could have been broken into sub-headings which would have better organized the section for the reader. Relatively speaking, however, these are negligible critiques and overall I fully endorse that all biologists and laypeople interested in wolves and their prey to buy this book. It has many pictures making it appropriate for your coffee table, and it is organized such that the reader can decide to browse thru the book and digest the important information, or - when having enough time - choose for an exhaustive, meticulous read and subsequent understanding of just how difficult it is to be a wolf. Perhaps Rolf Peterson best described the book in the Foreword (p. x) stating, "If wolves could read, this might very well be their favourite book".

$$
\text { JONATHAN (JON) WAY }
$$

Eastern Coyote/Coywolf Research, 89 Ebenezer Road, Osterville, MA, USA, 02655 